\title{
EfFect of SWeat Aggressiveness on Parameters of SURFACE INTEGRITY
}

\author{
Martin Melichar, Jan Kutlwaser, Dana Kubatova \\ University of West Bohemia,Univerzitni 8, Pilsen 306 14, Czech Republic
}

\begin{abstract}
Demands of product precision in chain supply in Automotive are on very high level. Usually there is focus on the fields of process control, productivity, reliability and repeatability of all the preparatory steps. But there is sometimes one area, which is in the background - protection of parts before sweat aggressiveness.

In this article there is analysis of influence of surface behavior of non-ferrous part by the sweat of the worker or operator. Research team had opportunity to observe and analyze influence of different level of sweat aggressiveness during controlled time-period to find out correlation between supply time, sweat and protection of high precision part for automotive industry.
\end{abstract}

Keywords: Sweat; aggressiveness; surface; integrity; metrology
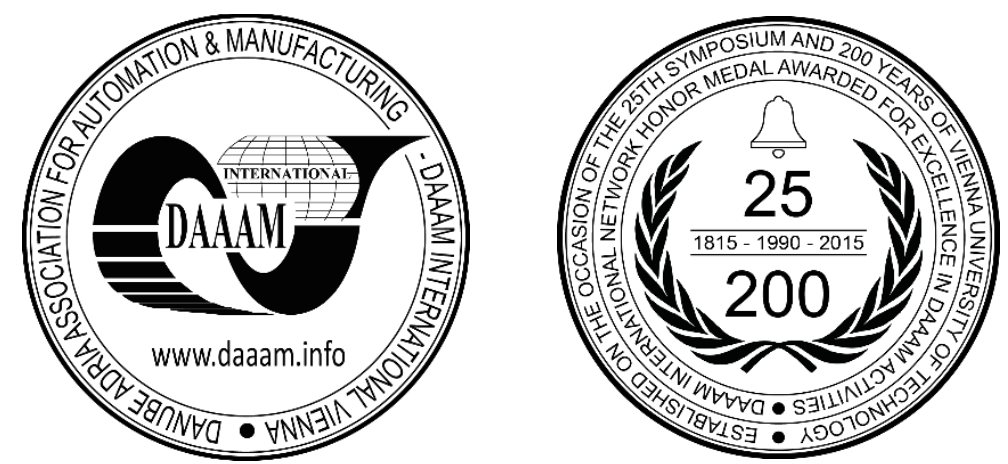

This Publication has to be referred as: Melichar, M[artin]; Kutlwaser, J[an] \& Kubatova, D[ana] (2016). Effect of Sweat Aggressiveness on Parameters of Surface Integrity, Proceedings of the 26th DAAAM International Symposium, pp.0536-0541, B. Katalinic (Ed.), Published by DAAAM International, ISBN 978-3-902734-07-5, ISSN 1726-9679, Vienna, Austria

DOI: $10.2507 / 26$ th.daaam.proceedings.073 


\section{Introduction}

The meaning of machining quality of the individual components increases recently. It has the major impact on the functionality of the entire device. Especially by the contact surfaces (eg. bearings) quality is roughness one of the decisive factors. It can influence the operation and use of the device as a whole. [3] The surface quality has a significant effect on the life and reliability of components, such as machine parts running accuracy, their noise, friction losses, heat transfer, or wear resistance. Therefore, it is preferable to monitor surface roughness of functional surfaces and evaluate the measured parameters. [3]

The surface structure has a decisive weight on how the component will behave in practice and what will have functional properties. General surface contains a number of unevenness (roughness, waviness, the surface shape) forming the surface structure, especially its differing pitches having a different effect on the function surface. Therefore, the development of measurement equipment and metrology surface structure needs to pay more and more attention.[1]

Surface structure from a customer perspective affects not only the basic material used tools and cutting conditions but very important process and product handling during production and the expedition.[2]

\section{Influence of aggression sweat}

The research team had the opportunity to cooperate closely with one of the leading assemblies suppliers in the automotive industry for leading automakers in Europe region. The university metrology lab was initially solved the problems of poor quality component subcontractors who supply Rotarex components.

The company uses the services of two certified suppliers, one is located in Luxembourg and the other has a production office in India. Both of these subcontractors supply identical products - Valve components of bronze alloy (see Fig.1) with high demands on precision and surface quality.

Although manufacturing conditions in both factory as the equipment material, machinery equipment and end product prices comparable, in practice, the supplied products have significant visually and functionally differences = valve units of the component from India often have a problem with leakage.

Initial dimensional and shape analysis conducted in metrology laboratories revealed significant differences and the actual difference ranged in the hundreds of units of micrometres, i.e. in the zone where they are in mass production for the automotive industry could be expected. Measurements were carried out on machines:

- CMM Carl Zeiss Prismo 7 Navigator- fixed head measurement uncertainty \pm 0.9 L / 350 micron

- Taylor Hobson 585 - measurement uncertainty of $0.02+0.0005 \mathrm{~mm} / \mathrm{micron}$. (see Fig.2, 3)

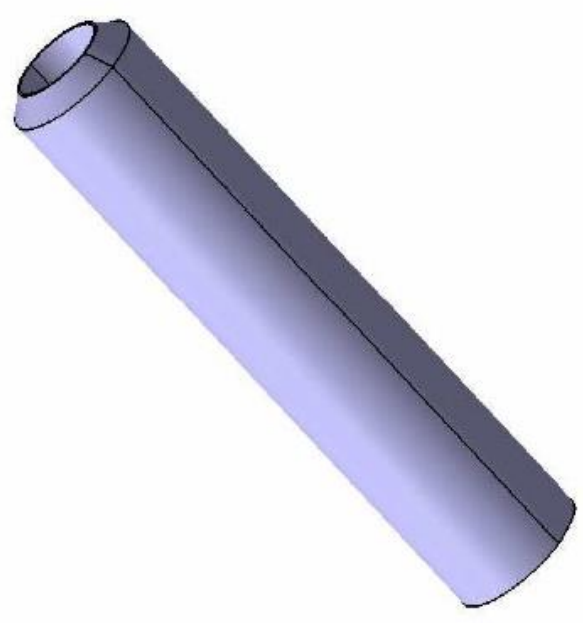

Fig. 1. Part 3D model 


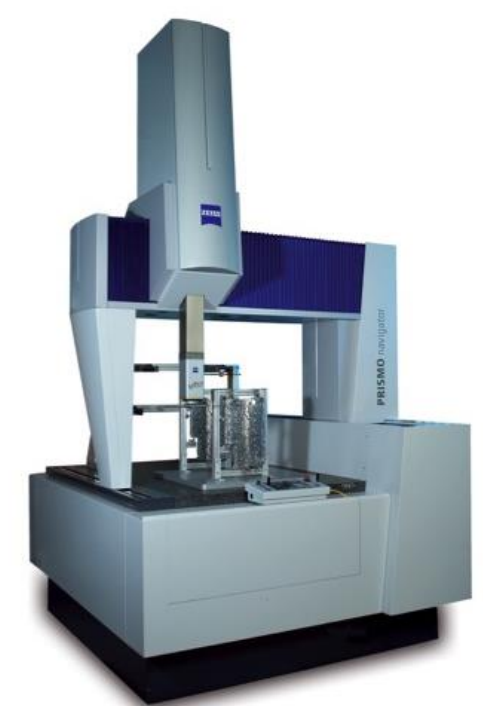

Fig. 2. CMM Carl Zeiss Prizmo 7 Navigator [5]

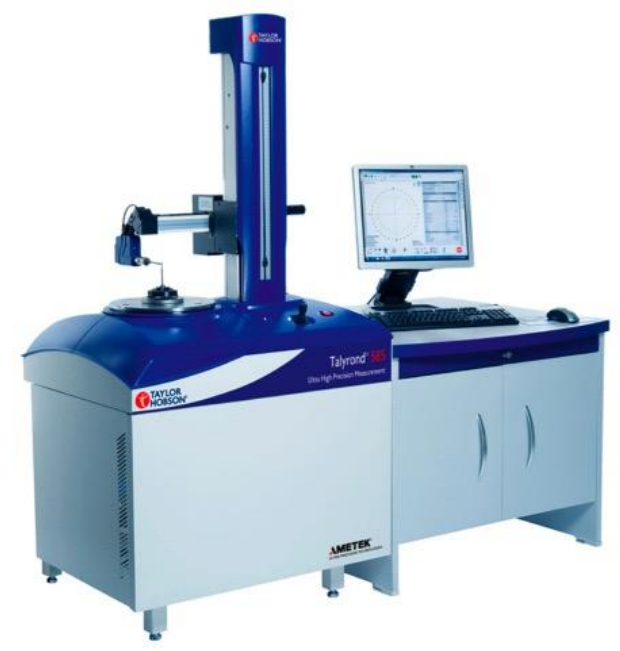

Fig. 3. Roundness machine Taylor Hobson Talyrond 585 LT [6]

As a second experiment was then tested the effect of aggression sweat on the parts with the assumption that higher parameters aggression sweat can potentially cause defects on the surface of parts and cause of that problem with leaks.

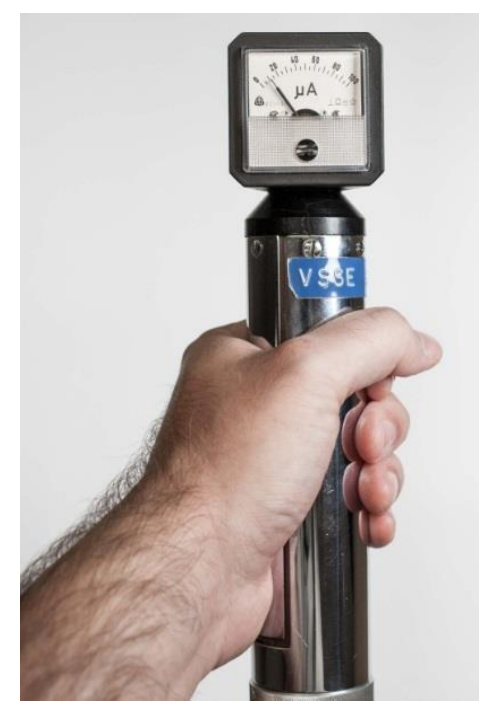

Fig. 4. Evaluation of sweat corrosion aggressiveness 


\begin{tabular}{ll}
\hline $\begin{array}{l}\text { Measured value } \\
(\mu \mathrm{A})\end{array}$ & Explanation \\
\hline $0-20$ & $\begin{array}{l}\text { the possibility of working with sensitive components without } \\
\text { specific requirements for subsequent cleaning and }\end{array}$ \\
$20-40$ & $\begin{array}{l}\text { requirements for subsequent purification preservation are increased } \\
\text { Without cleaning and conservation worker causes corrosion of } \\
\text { nonferrous metals } \\
\text { unprotected worker is not suitable for installation (corrosion in } \\
\text { hours) } \\
60-80\end{array}$ \\
$80-100$ & worker causes corrosion even without direct contact \\
\hline
\end{tabular}

Table 1. An evaluation of sweat corrosion aggressiveness measurement [4]

For the experiment itself has been carefully selected group of test subjects = students with current throughput body electrocution respectively $30,40,50,70$ and $100 \mu \mathrm{A}$. For selection of test subject was used a measurement device (see Fig. 4), which shows the actual corrosion aggressiveness of sweat represented by a value in $\mu \mathrm{A}$ (see Table 1). The Company Rotarex s.r.o. supplied equivalent parts, which have been previously cleaned with isopropyl alcohol. Each of the test subjects kept one part in a clenched fist for 10 seconds, which should adequately simulate contact with the worker in the manufacturing and handling process. All parts were during experiment manipulated only by the research team and only in the vinyl gloves. The parts were placed on labelled $\mathrm{pH}$ neutral pads and placed in the area of accurate metrological laboratory of Regional Technology Institute.

Environmental conditions were throughout the experiment completely still:

- $\quad$ Temperature: $20 \operatorname{deg} \mathrm{C}= \pm 0.5$,

- Humidity: $50 \%$

Two types of tests were done in two series - visual inspection (See Fig. 5, 6) + control of surface roughness and after 1 week and after 4 weeks from realization of the experiment. These time intervals were chosen because they properly simulate the normal delivery time from a subcontractor Luxembourg (one week) and India (four weeks).

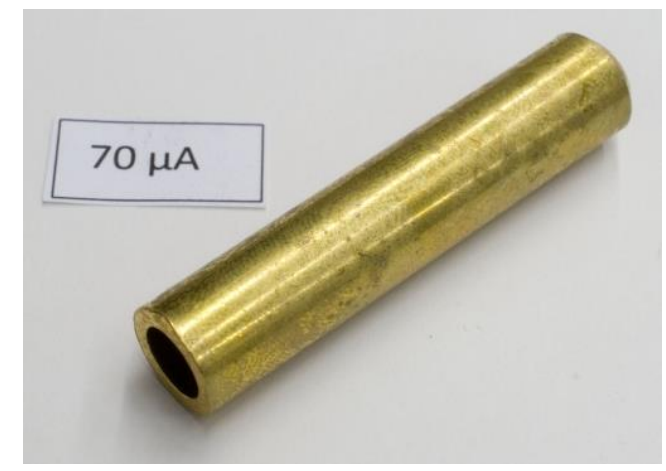

Fig. 5. Part after 1week

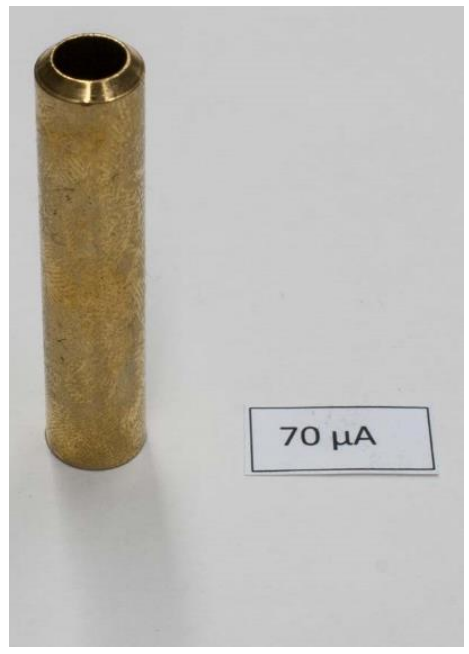

Fig. 6. Part after 4 weeks 
Already on visual inspection, it was clear that parts of the test cycle after a month cannot at best will withstand increased pressures acting within the assembly. Supplementing roughness control then showed that there was a change of surface roughness parameters $\mathrm{Ra}, \mathrm{Rz}, \mathrm{Rq}$ tens of percent, which exceeded all the roughness tolerance in the manufacturing drawing. See Fig.7,8.

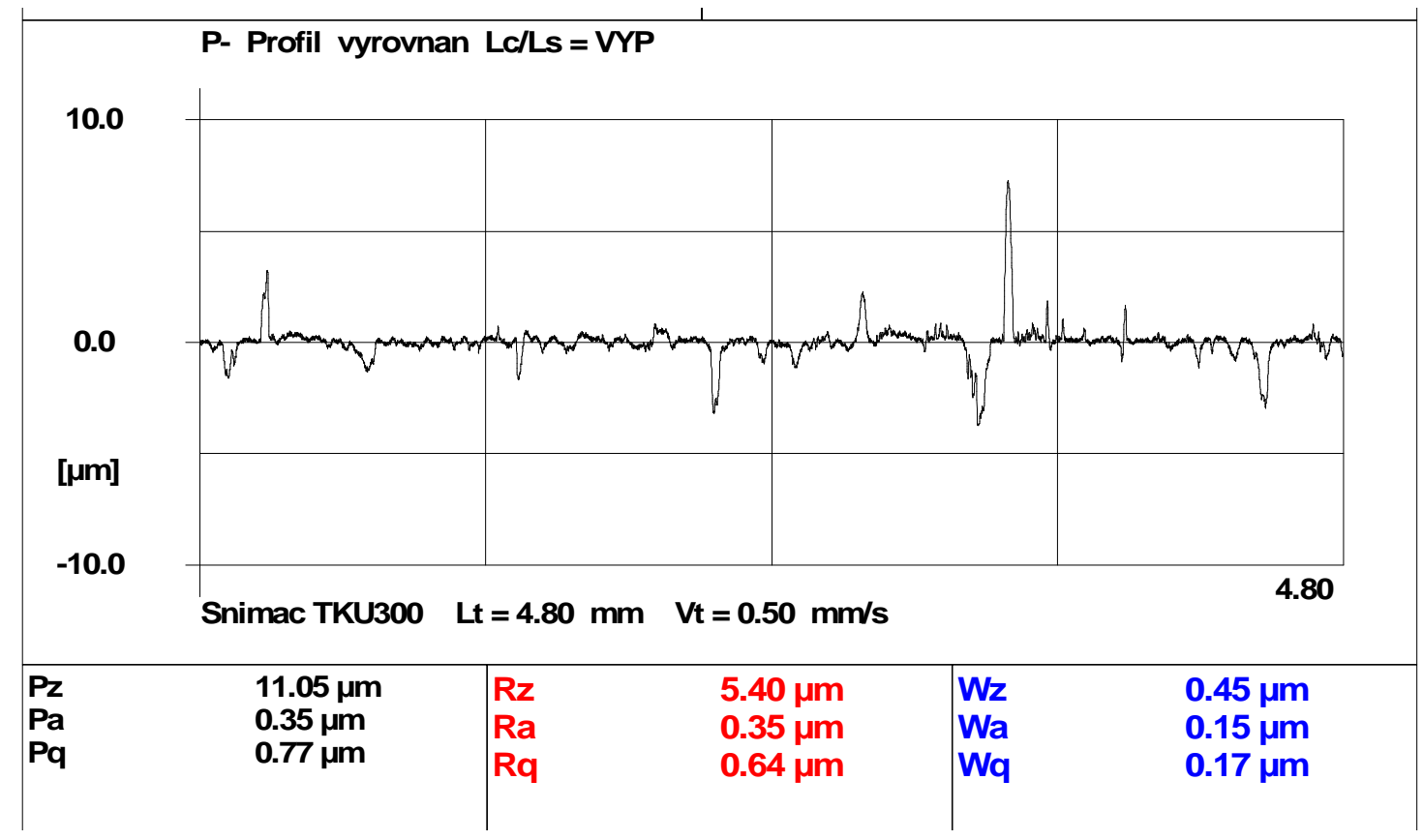

Fig. 7. Roughness measuring protocol

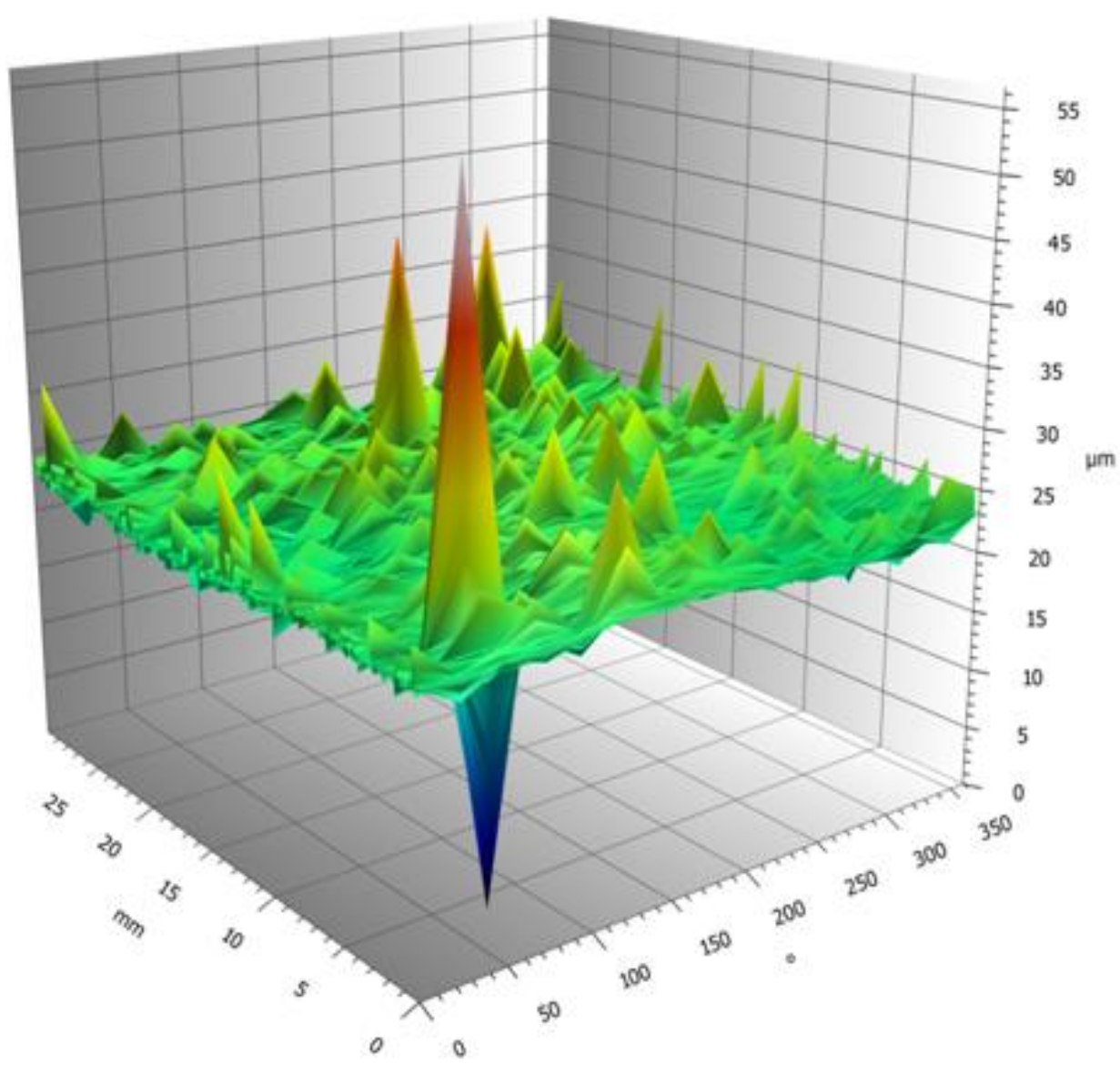

Fig. 8. 3D analysis of the surface 


\section{Figures}

Based on the experiment, the complex protection system of components for company was designed and will be implemented in the supply chain. For parts supplied from Luxembourg it has been proposed to use the protection liquids. Parts of India it is then necessary to use specific solid base or the base film preservatives. Parts supplied from India are probably transported by ship over the ocean. In this case could be considered usage of a corrosion inhibitor, like benzotriazole[7]. There is also possibility to use a corrosion monitoring and management approach described in [8].

\section{Conclusion}

The Experiment Provides statistical stable results and is a worthy example of how financially very undemanding intervention significantly improve or increase the entire production process and chain attached to it. The original intention to reveal the source of nonconformity in outsourcing critical parts for the automotive was completely filled. By the realized experiment it was verified that decisive influence on the integrity of the surface is surprisingly not only material, methodology and set of machine-tool, but also protect components against corrosion caused by aggressive sweat. Laboratory of Metrology RTI Pilsen thanks to obtain references and is currently preparing an extensive experiment to test a wider range of materials for a longer period of time for which private entities have shown great interest.

\section{Acknowledgements}

The present contribution has been prepared under project SGS031-2013 and project LO1502 'Development of the Regional Technological Institute ' under the auspices of the National Sustainability Programme I of the Ministry of Education of the Czech Republic aimed to support research, experimental development and innovation.

\section{References}

[1] JA Wharton, KR Stokes, The influence of nickel-aluminium bronze microstructure and crevice solution on the initiation of crevice corrosion, Electrochimica Acta, Volume 53, Issue 5, 2008, p. 2463-2473, ISSN 0013-4686, http: //dx.doi.org/10.1016/j.electacta.2007.10.047.

[2] RC Barik, JA Wharton, RJK Wood, KS Tan, KR Stokes, eroze a eroze-koroze výkon obsazení a tepelně stříkané nikl-hliník bronz, oblečení, Volume 259, Vydání 1-6, červenec-srpen 2005 Stránky 230-242, ISSN 0043-1648, http://dx.doi.org/10.1016/j.wear.2005.02.033.

[3] ND Meeks,., TIN-rich surfaces on bronze-some experimental and archaeological considerations. Archaeometry, 28: 133-162. doi: $10.1111 / \mathrm{j} .1475-4754.1986 . t b 00383 . x$

[4] A device for measurement of corrosion aggressiveness of sweat [on-line], [cit. 2015-08-29]. Available at: http://web.tuke.sk/smetrologia/pdf/potomer.pdf

[5] Carl Zeiss product figures for press, available on-line at: http://www.zeiss.de/corporate/de_de/medienforum/pressebilder/ produkte/industrielle-messtechnik.html\#portalmessgeraete, cited 2015-08-29

[6] Taylor Hobbson Talyrond 565/585 brochure, available on-line at: http://www.taylorhobson.com.br/pdf/175_espec.pdf, cited 2015-08-29, Taylor Hobbson, 2011.

[7] S. Neodoa, D. Carugob, J.A. Whartona, K.R. Stokes, Electrochemical behaviour of nickel-aluminium bronze in chloride media: Influence of $\mathrm{pH}$ and benzotriazole, Journal of Electroanalytical Chemistry, vol. 695, p. 38-46, 2013, Elsevier

[8] William M. Cox , A Strategic Approach to Corrosion Monitoring and Corrosion Management, Procedia Engineering, Structural Integrity, vol. 86, 2014, p. 567-575, Elsevier.

[9] Gokcen Bas, Lachezar Stoev, Numan M. Durakbasa, Assessment of the Production Quality in Machining by Integrating a System of High Precision Measurement, Procedia Engineering, vol. 100, 2015, p. 1616-1624, Elsevier. 